\title{
The effects of illuminance, color temperature and color rendering index of light sources upon comfortable visual environments - in the case of office -
}

\author{
Tenji WAKE*, Tadashi KIKUCHI*, Keishiro TAKEICHI* \\ Masaru KASAMA** and Hisashi KAMISASA***
}

\begin{abstract}
In the present experiment, the effects of illuminance upon comfortable visual environments of a room were examined by using a miniature room. The room was set to simulate an usual office. The light source was placed above the ceiling made of opaque acrylic plate. The room was lighted through the ceiling, using six kinds of lamps. Under various lighting conditions, subjects were required to rate the office according to the psycological method, which consisted of the "Image" and "evaluation" tests. For each of the tests, the scale values obtained by the method of successive categories were subjected to principal components analysis. As the results of the analysis, four components were extracted for both the "image" and the "evaluation" tests, accounting for $95 \%$ and $90 \%$ respeotively. The canonical correlation analysis was applied and indicated that the relation between two tests was very strong. In both tests, the first component closely related to illuminance, color temperature and color rendering, and strong depencence of the second component upon illuminance was found. The relationships between the scale values:of individual items and illuminance were discussed.
\end{abstract}

\section{Introduction}

The most serious problem is the fact that the quality of visual environments must be assessed by a human being. However, there is no generalized method for evaluating the environments except the CIE recommendation (Inui, 1970) ${ }^{1 \text {. }}$.

Wake, Kamisasa and Oyama $(1973)^{6)}$ have proposed a new method, and have applied it to examine the characteristics of visual environments. The method was consisted of check lists based on CIE's items, and "image" test which was similar to the semantic differential method (Osgood, Suci, and Tannenbaum, 1957) ${ }^{3}$. In their study, subjects observed the inside of a miniature room through a viewing window of it, and rated various psychological aspects of the room. According to their results, three components were extracted statistically, and it was found that illuminance on a floor played the most important role.

On the other hand, Kurithof $(1941)^{2)}$ reported

\footnotetext{
* Industrial Products Research Institute

** Iwasaki Electric Co., Ltd.

*** Tsukuba University
}

that for every color temperature there existed the highest and the lowest levels of illuminance at which the illumination was considered "pleasing". Although such a finding implies that "pleasing" depends upon illuminance and color temperature, it is not evident whether the other psychological aspects except "pleasing" are explained by them. Moreover, in his paper the method and procedure were not described in detail.

Since the original investigations of Kruithof, numerous experiments have been performed to examine the effect of color adaptation under various lighting conditions. Although these experiments were performed in simple experimental situations, it has been shown that color temperature and general color rendering index were important factors in some of psychological aspects.

In the present experiment, the effects of illuminance and color temperature upon psychological estimation were examined systematically. Furthermore, the relationships between the obtained factors and the physical amounts were discussed. 


\section{Method}

\section{Apparatus}

A miniature room box and a light housing were used in this experiment. They have been designed with as much flexibility as possible. The basic scale of one fifth has been chosen. The real size of the floor was $100 \mathrm{~cm}$ in width and depth, and the real height from the floor to the ceiling was $56 \mathrm{~cm}$. Therefore the simulated room was supposed to be $280 \mathrm{~cm}$ in height and $500 \mathrm{~cm}$ in width and depth.

In this apparatus, it is easy to change the material and color of the wall and floor, and the way of the illumination and light source.

In this experiment, the room was set to simulate an usual office. Miniature office desks, chairs, sofas and other office supplies were prepared and arranged (Fig. 1). Munsell Values of the floor, wall and face of a doll are 7.5PB3.1/5.1, N=8.0, 2.5YR6.0/4.3, respectively. CIE $(x, y, Y)$ chromaticy coordinates of the floor, wall and face of a doll under various lighting conditions are shown in Table 1.

The light housing can provide for many kinds of light sources. In this experiment, six kinds of lamps were used; high pressure sodium lamp, high pressure mercury lamp, high pressure mercury fluorescent lamp, incandescent lamp, fluorescent

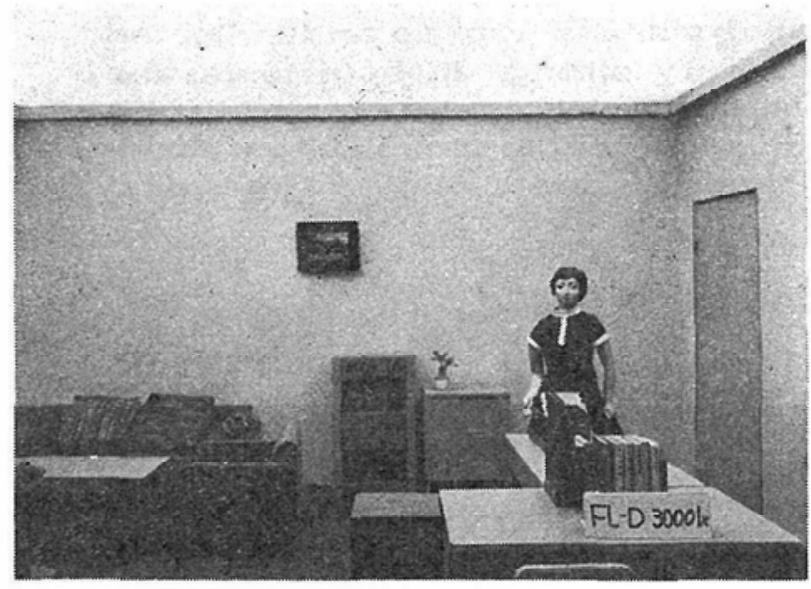

Fig. 1 Picture of the inside of the simulated room.

Table 1 Chromaticity Coordinate of the things in the simulated room.

\begin{tabular}{|c|c|c|c|}
\hline \multirow{2}{*}{ Kinds of laps } & \multicolumn{3}{|c|}{ CIE Chromaticity Coordinatee } \\
\hline & Wall & Floor & Face of doll \\
\hline $\begin{array}{l}\text { High pressure sodium } \\
\text { lamp }\end{array}$ & $\begin{array}{ll}x & 0.5483 \\
y & 0.4146 \\
Y & 0.5660\end{array}$ & $\begin{array}{l}0.4677 \\
0.3879 \\
0.4627\end{array}$ & $\begin{array}{l}0.5758 \\
0.4110 \\
0.9443\end{array}$ \\
\hline Incandescent lamp & $\begin{array}{ll}x & 0.4700 \\
y & 0.4199 \\
Y & 0.5624\end{array}$ & $\begin{array}{l}0.3231 \\
0.3753 \\
0.6207\end{array}$ & $\begin{array}{l}0.5408 \\
0.4149 \\
0.8154\end{array}$ \\
\hline $\begin{array}{l}\text { High pressure mercury } \\
\text { fluorescent lamp }\end{array}$ & $\begin{array}{ll}x & 0.4115 \\
y & 0.4136 \\
Y & 0.5647\end{array}$ & $\begin{array}{l}0.2976 \\
0.2912 \\
0.5640\end{array}$ & $\begin{array}{l}0.4858 \\
0.2912 \\
0.8090\end{array}$ \\
\hline $\begin{array}{l}\text { High pressure mercury } \\
\text { lamp }\end{array}$ & $\begin{array}{ll}x & 0.3550 \\
y & 0.4215 \\
Y & 0.5648\end{array}$ & $\begin{array}{l}0.2620 \\
0.2748 \\
0.5917\end{array}$ & $\begin{array}{l}0.4252 \\
0.4804 \\
0.7752\end{array}$ \\
\hline $\begin{array}{l}\text { Flourescent lamp } \\
\text { (White) }\end{array}$ & $\begin{array}{ll}x & 0.4057 \\
y & 0.4202 \\
Y & 0.5632\end{array}$ & $\begin{array}{l}0.2770 \\
0.3174 \\
0.6204\end{array}$ & $\begin{array}{l}0.4833 \\
004437 \\
0.7819\end{array}$ \\
\hline $\begin{array}{l}\text { Fluorescent lamp } \\
\text { (Daylight) }\end{array}$ & $\begin{array}{ll}x & 0.3359 \\
y & 0.3806 \\
Y & 0.5611\end{array}$ & $\begin{array}{l}0.2183 \\
0.2608 \\
0.7149\end{array}$ & $\begin{array}{l}0.4288 \\
0.4342 \\
0.7289\end{array}$ \\
\hline
\end{tabular}

Table 2 Color temperature, color rendering index and illuminance of the lamps.

\begin{tabular}{|c|c|c|c|}
\hline Lamps & $\mid \begin{array}{c}\text { Color } \\
\text { temperature }\end{array}$ & $\begin{array}{c}\text { Color } \\
\text { rending } \\
\text { index }\end{array}$ & Illuminance (Lux) \\
\hline $\begin{array}{l}\text { High pressure sodium } \\
\text { lamp }\end{array}$ & $2100 \mathrm{~K}$ & 29 & $\begin{array}{l}99,192,289,590,938, \\
1842,3100,4552,8800 .\end{array}$ \\
\hline Incandescent lamp & $2865 \mathrm{~K}$ & 100 & $\begin{array}{l}41,98,208,296,599 \\
995,1997,2963\end{array}$ \\
\hline $\begin{array}{l}\text { High pressure mercury } \\
\text { fluorescent lamp }\end{array}$ & $4200 \mathrm{~K}$ & 40 & $\begin{array}{l}210,300,600,1068 \\
2018,3167,5050 .\end{array}$ \\
\hline $\begin{array}{l}\text { High pressure mercury } \\
\text { lamp }\end{array}$ & $5700 \mathrm{~K}$ & 25 & $\begin{array}{l}293,610,1048,1983 \\
3100,5008\end{array}$ \\
\hline $\begin{array}{l}\text { Fluorescent lamp } \\
\text { (Daylight) }\end{array}$ & $6500 \mathrm{~K}$ & 77 & $\begin{array}{l}196,298,613,1007, \\
2050,2800 .\end{array}$ \\
\hline $\begin{array}{l}\text { Fluorescent lamp } \\
\text { (white) }\end{array}$ & $4500 \mathrm{~K}$ & 69 & $\begin{array}{l}198,307,617,957, \\
2043,2850 .\end{array}$ \\
\hline
\end{tabular}

lamp (white) and fluorescent lamp (daylight). The color temperature and general color rendering index are shown in Table 2, and relative spectral energy distributions of the lamps are shown in Fig. 2. The ceiling was made of acrylic plate. It was inserted between the light housing and the room box. The room was illuminated through the ceiling (luminous ceiling).

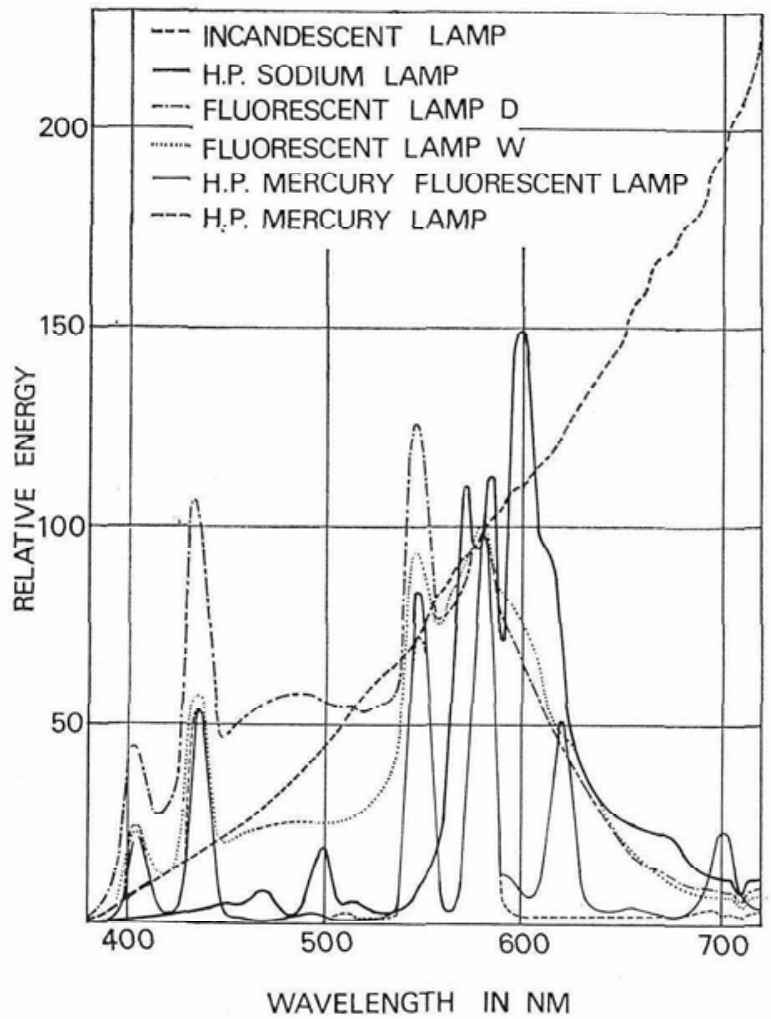

Fig. 2 Relative spectral energy distributions of the lamps.

The illuminance on the floor was vaired by mounting filters (black wire netting), which were inserted between the light source and the ceiling. The illuminance was measured at five points on the floor and was averaged. The obtained illuminances under various lighting conditions are shown in Table 2.

\section{Procedure}

The subjects were asked to observe the inside of the room through a small viewing window of it, and were required to rate the office on 40 -adjective scales ("image" test) and 25-items for evaluating the various aspects of the office ("evaluation" test). 
Prior to rating, the subjects were required to see the inside of the office for several minutes in order to adapt to the lighting conditions.

The "image" and "evaluation" tests were the same as those used in the previous study (Wake, Kamisasa, and Oyama, 1973) ${ }^{6}$. The adjectives and items were used originally in Japanese, whose English near-equivalents are shown in Tables 3 and 4. In the "image" test, the subjects were asked whether their immediate impressions of the room fitted each of the scales or not, and the degrees of fitness or unfitness were rated by using a 7-point scale. In the "evaluation" test, they were instructed to judge the various aspects of the room under the various lighting conditions. A 7-point rating form was also used, where it was supposed that 7 means "very good" and 1 means "very bad".

The presentation order of the lighting conditions to subject was determined at random with the restriction that the same light source was not used in succession. Several subjects were grouped, and the experiment was performed by rotation in order to save time and to avoid the subjects being fatigued.

\section{Subjects}

Forty-eight subjects served in this experiment. The age of them was from fifteen to thirty-seven. About a half of them were male. They were students, office workers, designers and researchers. Their color vision was normal.

\section{Results}

The rating scores of the lists under various lighting conditions were defined on the 7-point scale. The rated values for each condition were scaled by the method of successive categories. Then intercorrelations among the 40-adjectives ("image") and among the 25-items ("evaluation") were computed. The resulting matrices were subjected to a principal components analysis separately, with the results displayed in Tables 3 and 4 .

The factor scores were estimated for each lighting condition to define the configurations in the "image" and "evaluation" spaces.

\section{"Image" test analysis}

The results of the analysis for the 40-adjective scales are shown in Table 3. As shown in Table 3, four components extracted account for $95.2 \%$ of the total variance.

For the first component, the adjectives having high loadings are as follows; vivid, open, free, young, fresh, bright, positive, gay, new, modern, beautiful, rich, healthy, broad, heavy, and novel. Thus the first component may represent a dimension of evaluation which Osgood, et al. (1957) ${ }^{3}$ found in the study of the semantic differential method. This component accounts for $63.47 \%$ of the total variance.

Fig. 3 shows the relationship between the factor score of the first axis and illuminance. The score increases with the increase of illuminance under all lighting conditions. However, the scores of high
Table 3 Results of the "image" test analysis.

\begin{tabular}{|c|c|c|c|c|c|}
\hline & \multirow[b]{2}{*}{ adjective } & \multicolumn{4}{|c|}{ loadings } \\
\hline & & I & II & III & IV \\
\hline 1 & calm & -0.0677 & 0.9631 & 0.1964 & 0.0010 \\
\hline 2 & bright & 0.9367 & -0.1934 & -0.1237 & -0.0162 \\
\hline 3 & pleasant & 0.7526 & 0.6110 & 0.1681 & -0.0590 \\
\hline 4 & open & 0.9842 & 0.0216 & -0.0034 & -0.0600 \\
\hline 5 & monotonous & 0.4899 & 0.6982 & -0.3064 & -0.0346 \\
\hline 6 & neat & 0.7254 & 0.6342 & -0.2239 & 0.0407 \\
\hline 7 & elegant & 0.6014 & 0.7710 & -0.0193 & 0.0682 \\
\hline 8 & clean & 0.8691 & 0.4467 & -0.1721 & 0.0154 \\
\hline 9 & rich & 0.9312 & -0.1056 & 0.2789 & -0.0685 \\
\hline 10 & balanced & 0.6004 & 0.7255 & 0.2530 & -0.0838 \\
\hline 11 & vivid & 0.9896 & 0.0591 & 0.0527 & -0.0140 \\
\hline 12 & new & 0.9471 & -0.0203 & -0.2092 & 0.1136 \\
\hline 13 & positive & 0.9615 & -0.1626 & -0.0195 & 0.0716 \\
\hline 14 & quiet & -0.4100 & 0.8930 & -0.0615 & 0.0409 \\
\hline 15 & young & 0.9725 & -0.0773 & -0.0591 & 0.0777 \\
\hline 16 & free & 0.9816 & -0.0245 & 0.0231 & 0.0420 \\
\hline 17 & in keeping & 0.2214 & 0.8940 & 0.2468 & -0.0548 \\
\hline 18 & gay & 0.9558 & -0.1321 & 0.2146 & -0.0451 \\
\hline 19 & novel & 0.9066 & -0.3024 & -0.1080 & 0.1018 \\
\hline 20 & warm & 0.4672 & -0.6049 & 0.6189 & -0.1230 \\
\hline 21 & soft & 0.2872 & -0.1010 & 0.9135 & -0.1909 \\
\hline 22 & healthy & 0.9251 & 0.0672 & 0.1869 & -0.0166 \\
\hline 23 & deluxe & 0.8964 & 0.0044 & 0.2571 & 0.0988 \\
\hline 24 & deep & -0.8047 & 0.4644 & 0.2375 & 0.0976 \\
\hline 25 & heavy & -0.9117 & 0.2593 & 0.1728 & 0.0600 \\
\hline 26 & cheerful & 0.8941 & -0.3551 & 0.2395 & -0.0505 \\
\hline 27 & beautiful & 0.9378 & 0.2436 & 0.0686 & -0.0096 \\
\hline 28 & interesting & 0.6555 & -0.6602 & 0.1919 & 0.1234 \\
\hline 29 & overcrowded & -0.5123 & -0.1016 & 0.4797 & 0.6837 \\
\hline 30 & modern & 0.9405 & -0.0441 & -0.2069 & 0.1114 \\
\hline 31 & in good taste & 0.8724 & 0.3790 & -0.2451 & 0.0579 \\
\hline 32 & dynamic & 0.8886 & -0.4055 & -0.0208 & 0.0740 \\
\hline 33 & gorgeous & 0.8712 & -0.4695 & 0.0488 & 0.0027 \\
\hline 34 & brilliant & 0.8589 & -0.4415 & -0.0517 & -0.0251 \\
\hline 35 & Iresh & 0.9693 & 0.1135 & -0.1296 & 0.0862 \\
\hline 36 & well organized & 0.4854 & 0.7980 & 0.1423 & 0.1270 \\
\hline 37 & restful & -0.1565 & 0.9011 & 0.3037 & 0.0192 \\
\hline 38 & broad & 0.9219 & 0.2945 & -0.1502 & -0.0350 \\
\hline 39 & harmonious & 0.7499 & 0.6333 & 0.0805 & -0.0262 \\
\hline 40 & striking & 0.8833 & -0.3995 & -0.0776 & 0.0803 \\
\hline & contribution & 0.6347 & 0.2358 & 0.0644 & 0.0171 \\
\hline
\end{tabular}

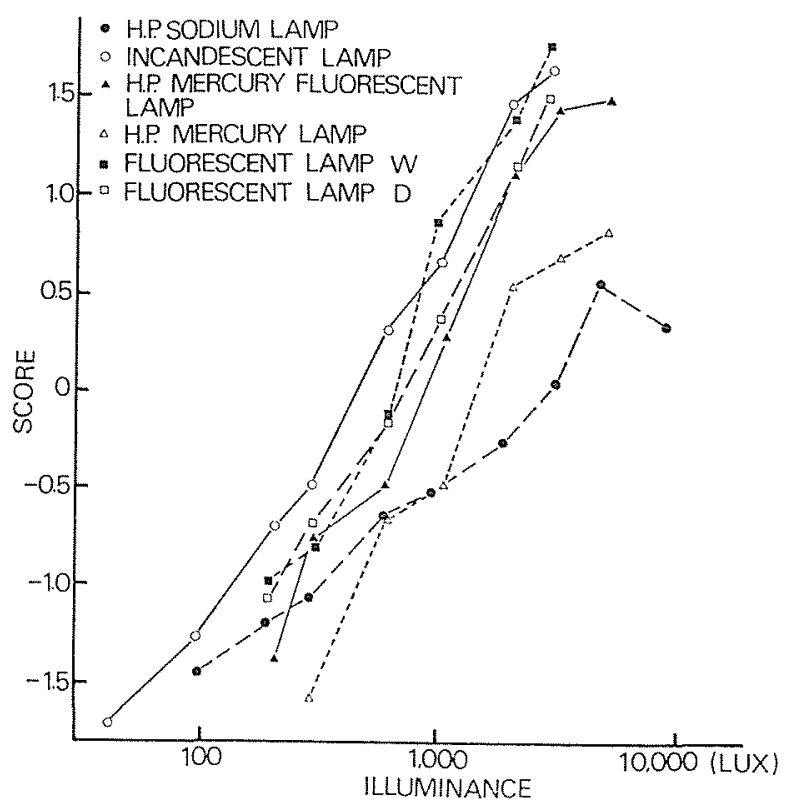

Fig. 3 Factor score of the first component as a function of illuminance (the "image" test). 
pressure mercury lamp and the high pressure sodium lamp are extremely smaller than those of the other lamps. As shown in Table 2, the high pressure mercury lamp and the high pressure sodium lamp are low in color rendering index. Thus, it may be concluded that the first component is determined by illuminance and color rendering.

The second component may be regarded as metal composure, because the adjectives such as calm, restful, in keeping, and quiet have high loadings to this component. It accounts for $23.58 \%$ of the total variance. This component is concerned with a dimension of activity as mentioned in studies on affetcive responses to colors.

The factor score of the second axis is plotted against illuminance in Fig. 4. All curves except the high pressure sodium lamp are nearly flat up to $2000 \mathrm{~lx}$, and then begin to drop, with the increase of illuminance. So this fact suggests that the effect of glare is likely to be reflected on this component.

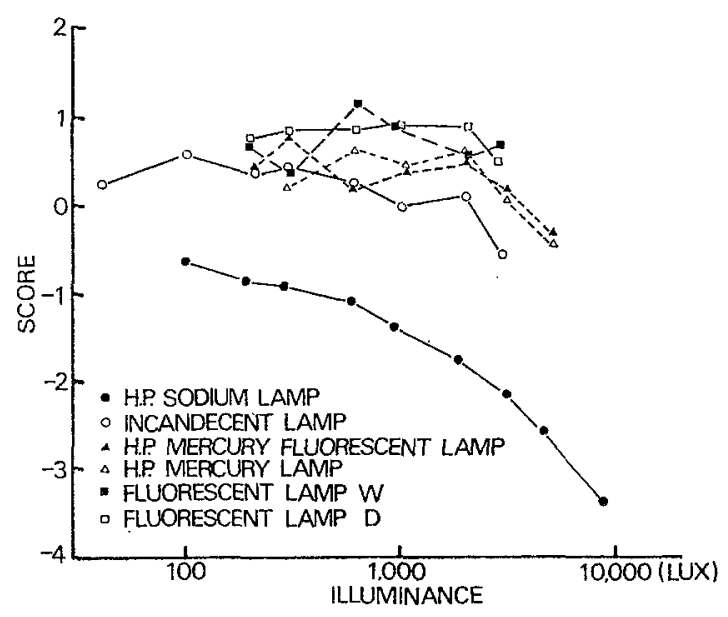

Fig. 4 Factor score of the second component as a function of illuminance (the "image" test).

Adjective scales having high loadings on the third component are soft and warm. This component which accounts for $6.44 \%$ of the total variance is concerned with a dimension of warm feeling or potency of affective responses to colors.

The relationship between factor score for the

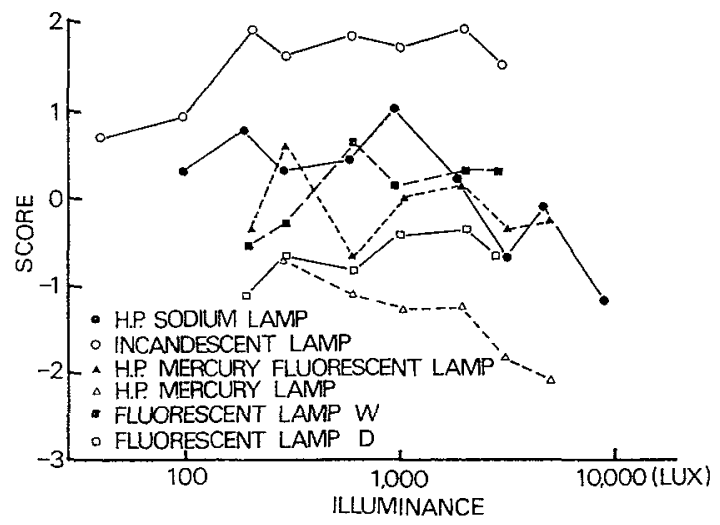

Fig. 5 Factor score of the thire component as a function of illuminance (the "image" test). third axis and illuminance is not clear as shown in Fig. 5. However, the score of the incandescent lamp is always positive, whereas the score of the high pressure mercury lamp is always negative and it shows a decrement trend with the increase of illuminance. The other scores exist between both lamps. It is inferred that the third component represents the differences of lamps. These seems to show a tendency that the lower the color temperature and the higher the color rendering index, the higher the scores.

The fourth component accounts for only $1.71 \%$ of the total variance. For this component, only the scale of overcrowded has high loading. No regular relation among the factor score, illuminance, color temperature and color rendering index is found. Thus, this component may be related to interiors in the room.

\section{"Evaluation" test analysis}

The results of the analysis are shown in Table 4. In this analysis, four components were extracted. These components accounts for $89.5 \%$ of the total variance. The first component accounts for $72.5 \%$ of the total variance. The items which indicate high loadings are the total impression (item 23),

Table 4 Results of the "evaluation" test analysis.

\begin{tabular}{|c|c|c|c|c|c|}
\hline \multirow{2}{*}{\multicolumn{2}{|c|}{ items }} & \multicolumn{4}{|c|}{ loadings } \\
\hline & & I & II & $\mathrm{III}$ & IV \\
\hline 1 & The material of the floor is & 0.7842 & 0.3505 & -0.1913 & -0.0003 \\
\hline 2 & The color of the floor is & 0.9115 & 0.2917 & -0.0773 & 0.0704 \\
\hline 3 & The material of the walls is & 0.8393 & -0.2137 & 0.1962 & 0.1232 \\
\hline 4 & The color' of the walls is & 0.9186 & -0.2221 & -0.0638 & -0.0204 \\
\hline 5 & The material of the ceiling is & 0.8870 & -0.0337 & 0.0655 & 0.0798 \\
\hline 6 & The color of the ceiling is & 0.9710 & -0.0022 & -0.0548 & 0.0284 \\
\hline 7 & $\begin{array}{l}\text { The material of the office } \\
\text { supplies is }\end{array}$ & 0.6494 & -0.2147 & -0.5862 & 0.1355 \\
\hline 8 & $\begin{array}{l}\text { The color of the office } \\
\text { supplies is }\end{array}$ & 0.8564 & 0.0069 & -0.1500 & 0.3575 \\
\hline 9 & $\begin{array}{l}\text { For the purpose of this room, } \\
\text { the brightness in the room is }\end{array}$ & 0.8960 & -0.3032 & 0.1030 & -0.1514 \\
\hline 10 & $\begin{array}{l}\text { The distribution of bright- } \\
\text { ness in the room is }\end{array}$ & 0.9191 & -0.2433 & 0.0495 & -0.1787 \\
\hline 11 & $\begin{array}{l}\text { In relation to the glare of the } \\
\text { light source, the illumination } \\
\text { of the room is }\end{array}$ & 0.2658 & 0.9405 & 0.0705 & 0.0299 \\
\hline 12 & $\begin{array}{l}\text { In relation to the reflection } \\
\text { from the surfaces of the floor, } \\
\text { walls and office supplies, the } \\
\text { illumination of the room is }\end{array}$ & 0.3637 & 0.9034 & 0.0918 & -0.0002 \\
\hline 13 & $\begin{array}{l}\text { The three dimensonal im- } \\
\text { pression under the illumina- } \\
\text { tion is }\end{array}$ & 0.8890 & -0.0145 & -0.1355 & -0.2553 \\
\hline 14 & $\begin{array}{l}\text { The illumination for the natu- } \\
\text { ral appearance of color is }\end{array}$ & 0.9365 & 0.1874 & -0.1307 & -0.0420 \\
\hline 15 & The color of light source is & 0.9736 & 0.1164 & -0.0794 & -0.0612 \\
\hline 16 & $\begin{array}{l}\text { The design of lighting equip- } \\
\text { ment is }\end{array}$ & 0.8980 & -0.0284 & 0.1265 & 0.0426 \\
\hline 17 & The height of the ceiling is & 09040 & -0.1144 & 0.2062 & -0.0014 \\
\hline 18 & $\begin{array}{l}\text { The ratio of the width to the } \\
\text { depth of the room is }\end{array}$ & 0.7606 & -0.0565 & 0.4827 & -0.1389 \\
\hline 19 & The size of the room is & 0.8079 & -0.3115 & 0.1111 & -0.1934 \\
\hline 20 & $\begin{array}{l}\text { The arrengement of the office } \\
\text { supplies is }\end{array}$ & 0.5227 & -0.2079 & 0.3137 & 0.7046 \\
\hline 21 & The method of illumination is & 0.9658 & -0.0761 & 0.0647 & -0.0583 \\
\hline 22 & $\begin{array}{l}\text { The color harmony of the } \\
\text { room is }\end{array}$ & 0.9689 & 0.0370 & 0.0264 & 0.0133 \\
\hline 23 & $\begin{array}{l}\text { The total impression of the } \\
\text { room is }\end{array}$ & 0.9838 & 0.0487 & -0.0474 & -0.0219 \\
\hline 24 & $\begin{array}{l}\text { The color appearance of the } \\
\text { room is }\end{array}$ & 0.9586 & 0.1697 & -0.0172 & 0.0077 \\
\hline 25 & $\begin{array}{l}\text { The total atmosphere of the } \\
\text { room is }\end{array}$ & 0.9469 & 0.0088 & 0.0275 & -0.1148 \\
\hline & contribution & 0.7251 & 0.0979 & 0.0375 & 0.0349 \\
\hline
\end{tabular}




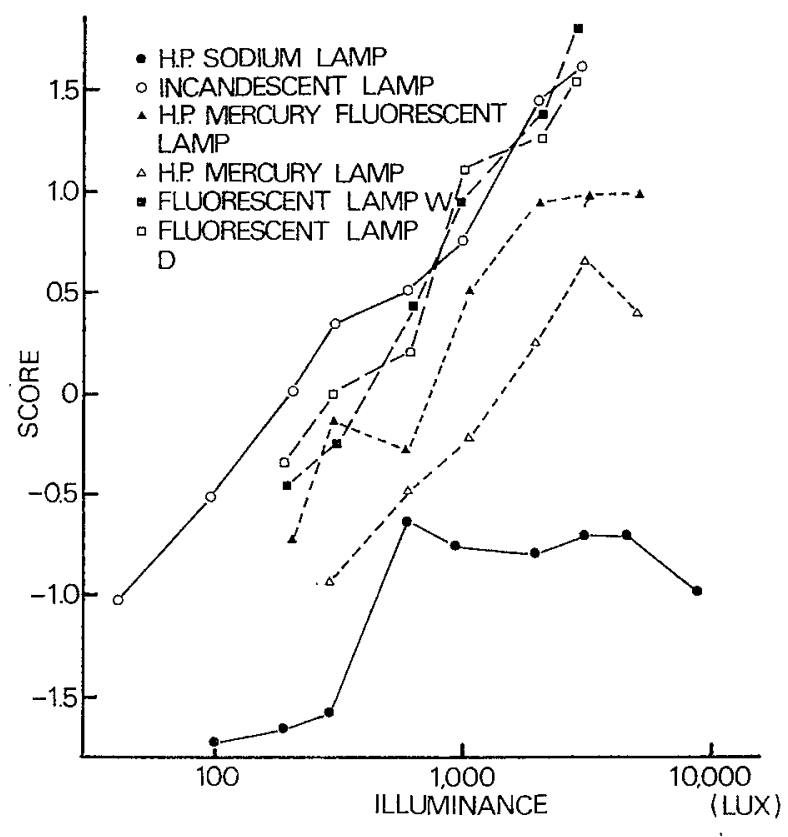

Fig. 6 Factor score of the first component as a function of illuminace:(the "evaluation" test).

the color of the light source (item 15), the color of the ceiling (item 6), the color harmony (item 22), the way of illumination (item 21), the color appearance of the room (item 24), the total atmosphere of the room (item 25) and others. These items will. be regarded as a general evaluation of the quality of illumination and atmosphere of the room.

Fig. 6 shows the relationship between the factor score of the first component and illuminance. The score increases with the increase of illuminance under all conditions except the high pressure sodium lamp. Furthermore, differences among lamps are found. These differences may be dependent upon color rendering index. As shown in Fig. 6, the factor scores of lamps with low color rendering index are smaller than those with high color rendering index.

The second component, which accounts for $9.8 \%$ of the total variance, represents a dimension of glare. Because the glare of light source (item 11)

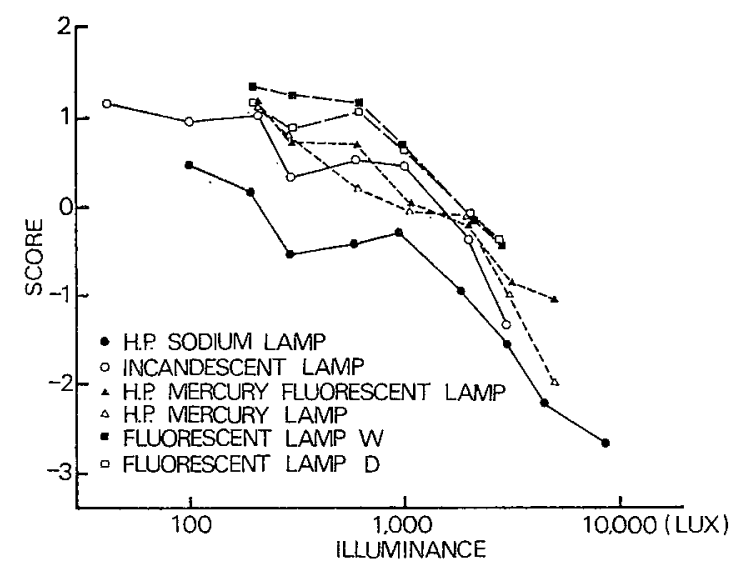

Fig. 7 Factor score of the second component as a function of illuminance (the "evaluation" test). and reflectance of the surface of the office supplies (item 12) have substantial loadings. Moreover, the factor score of this component decreases with the increase of illuminance, and large differences among lamps are not found (Fig. 7). Thus, this component is considered to be a dimension of glare, and illuminance plays an important role.

The third component, which accounts for $3.75 \%$ of the total variance, may be regarded as constructional factor of the room. For this component, the material of the office suppoties (item 7) and the ratio of the width to the depth of the room (item 18) show high loadings.

For the fourth component which accounts for $3.49 \%$ of the total variance, only the arrangement of the office supplies (item 20) has high loading. This component may represent interiors of the room. No clear relations among the factor scoers, illuminance, color temperature and color rendering index are found for these two components.

Wake, Kamisasa and Oyama $(1973)^{\circ)}$ have shown similar results. However, there is a discrepancy between both works. Four components were extracted in their work. According to their results, the first component was a general evaluation of the quality of illumination, the second one, glare, and the third one, the spacial characteristics of the room. This discrepancy may be interpreted as a difference of number of subjects. Moreover, when the factor score of the first component was plotted against illuminance, it increased progressively with the increase of illuminance and the difference among lamps was extremely small. As shown in Fig. 6 in this paper, however, there was a large difference among lamps. Such a discrepancy may be due to the difference of color rendering index of lamps used in both experiments.

\section{Canonical correlation analysis}

In order to establish the evaluation method of visual environments based on subjective estimation methods, it is desired to clear the relationship between the "image" and "evaluation" tests, and to select the proper check lists from both tests. The canonical correlation analysis was applied. This analysis calculates the maximum correlation between linear composites (canonical variates) of the two sets of variates of the same objects. This analysis may also be regarded as a method of measuring the amount of variance common to the two sets of variates of the same objects. The weights applied to original variates in order to obtain the canonical variates indicate the relative contribution of the original variates to each canonical variates. This weight is often called the canonical weight. The results of the analysis indicate that the maximum canonical correlation is .986 and it is significant beyond .005 level according to Bartlett's $X^{2}$ approximation. The second canonical correlation is .965 , which is also significant beyond .005 level. The third one is .463, which is significant at .1 level. The contribution that canonical variates are significant in the individual dimensions is shown in Table 5 . 
Table 5 Contribution of the individual components to the significantly related canonical variates

\begin{tabular}{|c|c|c|c|c|c|c|c|c|}
\hline \multirow{3}{*}{$\begin{array}{l}\text { canonical } \\
\text { correlation }\end{array}$} & \multicolumn{8}{|c|}{ canonical weight } \\
\hline & \multicolumn{4}{|c|}{ "image" } & \multicolumn{4}{|c|}{ "evaluation" } \\
\hline & I & II & III & IV & I & II & III & IV \\
\hline 1.986 & $|-0.865|$ & $\mid-0.504$ & -0.029 & -0.008 & -0.987 & 0.098 & -0.098 & 0.082 \\
\hline 2.965 & 0.492 & -0.827 & -0.265 & 0.055 & -0.115 & $-0.981 \mid$ & $0.047^{\circ}$ & -0.146 \\
\hline 3.463 & -0.108 & 0.219 & -0.760 & 0.602 & -0.102 & 0.082 & 0.979 & -0.155 \\
\hline
\end{tabular}

The squared canonical correlations may be interpreted as the proportion of the variance common to their individual canonical variates. The first set of canonical variates shares $97.34 \%$ common variance. The common variance of the second set is also high, i.e., $93.17 \%$. That of the third set is $21.44 \%$, and that of the fourth is almost zero. Thus we infer that there are at least two or three significant ways in which the two spaces are related.

The total variance shared by the two spaces is obtained by squaring and summing the canonical correlations and then dividing this sum by four. The result of this computation shows that the total variance shared by the two spaces is $53.1 \%$.

\section{Discussion}

In the present study, the two types of questionaire tests were applied to estimate subjective characteristics of the visual environments (i.e., the inside of the simulated room). From each of the tests, four components were extracted. In the results of the "image" test, four components have been called evaluation, activity, potency and "overcrowded". According to many works regarding affective responses to colors, three or four components have been extracted, and they have been named evaluation, activity and potency (Oyama, Soma, Tomiie and Chiziiwa, $1965^{4)}$; Tomiie, $1969^{\text {(j) }}$ ). In the work of affective responses to colors, the subjects observed a color or multiple colors and the semantic differential method was applied, while in the present study the simulated room which was similar to a real visual environment was employed. It is very interesting that the results of this study is quite similar to their studies.

From canonical correlation analysis, it is shown that there are high relations between the corresponding components of the both tests. However, there is a difference between both tests that the first component in the "image" test accounts for $63.47 \%$ of the total variance, whereas the first component in the "evaluation" test accounts for $72.51 \%$. This difference will depend upon the difference of the questionaire tests used. Oyama, Soma, Tomiie and Chiziiwa $(1965)^{4)}$ found that the evaluation component accounted for $31.4 \%$ of the total variance. Therefore it may be considered that the contribution of the first component depends upon the measuring method and the stimulus situation.

Fig. 8 shows the subjective values for "bright", one of the adjectives of the "image" test, as a function of illuminance. The scale value was calculated

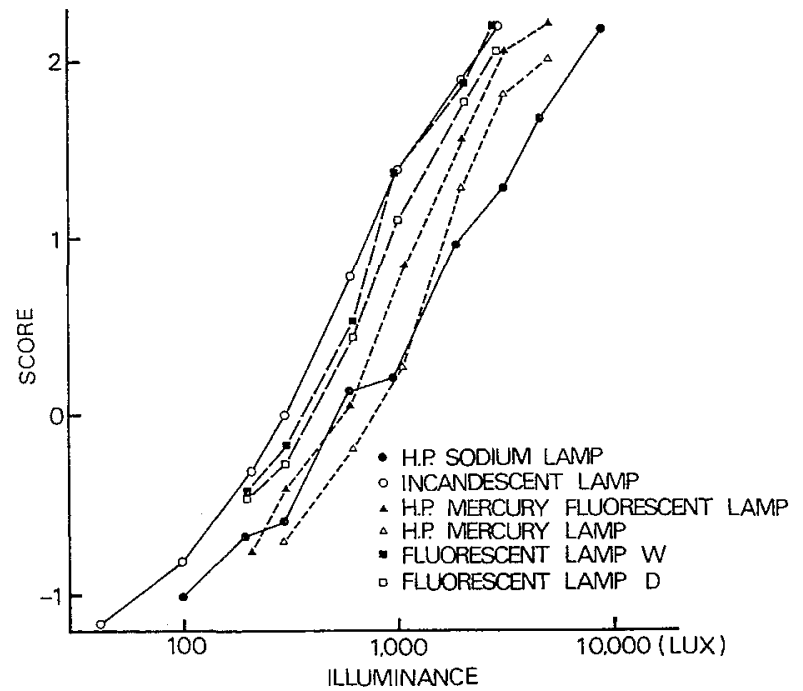

Fig. 8 Scale value of the adjective "bright" as function of illuminance.

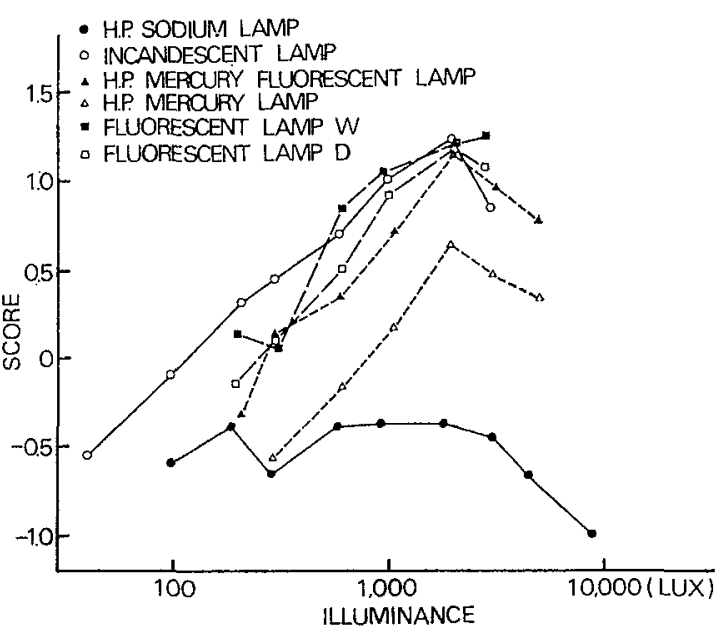

Fig. 9 Scale value of the adjective "pleasant" as a function of illuminance.

by the method of successive categories. The scale value in Fig. 8 increases linearly with the increase of illuminance, and the differences among lamps are extremely small. However, the effect of color rendering index upon the scale value is slightly observed. That is, the subjective values for high color rendering index lamps are always higher than those for low color rendering index lamps. The effect of illuminance upon "pleasant" is shown in Fig. 9. The scale value increases with the increase of illuminance up to about 2,000 lx, and then begins to drop under all conditions except the high pressure sodium lamp. In the case of the high pressure sodium lamp, the scale value does not increase with the increase of illuminance, but the drop of the value beyond $2,000 \mathrm{~lx}$ is also observed. A large difference of the values among lamps is found in Fig. 9.

Kruithof $(1941)^{2)}$ showed the relationship between illuminance and color temperature about pleasantness. In his study, at a given level of illuminance it is found that color temperature must lie within a certain limit in which the effect of illumi- 
nance is "pleasing". That is, there is an optimum range of illuminance at a certain color temperature, and its range varies with the increase of color temperature. As shown in Fig. 9, the rating score for the high pressure sodium lamp $(2100 \mathrm{~K})$ is always negative. No pleasant range is found. In the case of the incandescent lamp $(2850 \mathrm{~K})$, however, there is an optimum range beyond $200 \mathrm{~lx}$. But the upper limit such as Kruithof's is not observed. The optimum range of the high pressure mercury fluorescent lamp $(4200 \mathrm{~K})$ and the fluorescent lamps $(4500 \mathrm{~K}$ and $6500 \mathrm{~K}$ ) is beyond $400 \sim 500 \mathrm{~lx}$. The optimum range of the high pressure mercury $(5700 \mathrm{~K})$ is beyond $800 \mathrm{~lx}$. Such a relationship between color temperature and illuminance upon pleasantness does not contradict with the Kruithof's data. However, there are a fow discrepancies between our data and his. The cause of the discrepancies may depend upon the lamps used. The lamp with $2100 \mathrm{~K}$ used in our study is the high pressure sodium lamp, and that with $5700 \mathrm{~K}$ is the high pressure mercury lamp. These lamps have extremely low color rendering index. Therefore further studies using the lamps with the same color rendering index will be needed.

According to Kruithof, if we see visual environments with illuminance below the optimum range, we shall have an impression of "dim" at low color temperature or "cold" at high color temperature. Moreover, if illuminance is above the optimum range, we shall perceive unnatural color, which will cause us unpleasant feelings. Thus "the natural appearance of color" (item 14) may deserve attention in our discussion. In Fig. 10, the results for item 14 are summarized. When illuminance is below about 1,000 lx, the scale value is negative under all conditions. In particular, the color appearance is extremely unnatural under the conditions of the high pressure sodium lamp and the high pressure mercury lamp. These lamps are very low in color rendering index. There is, however, no observation of unnatural appearance of color under high illuminance conditions. A similar result is obtained

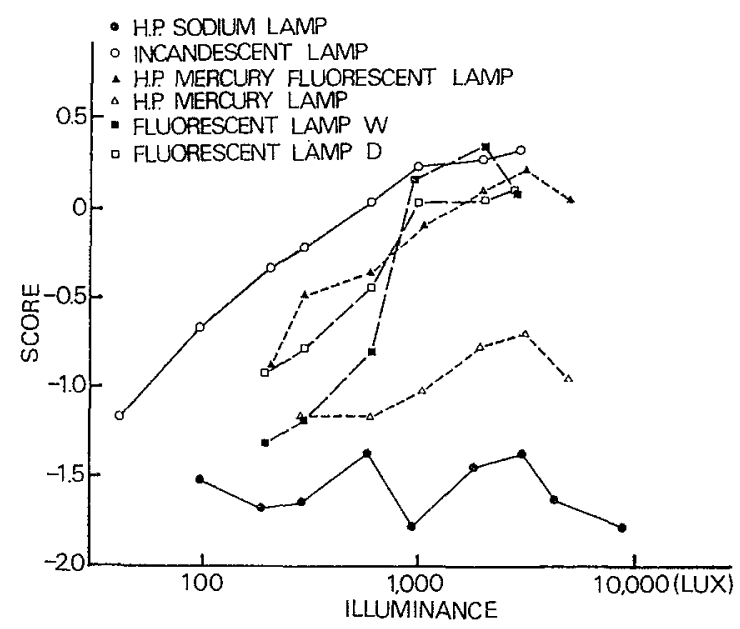

Fig. 10 Scale value of "the natural appearance of color" (item 14) as a function of illuminance.

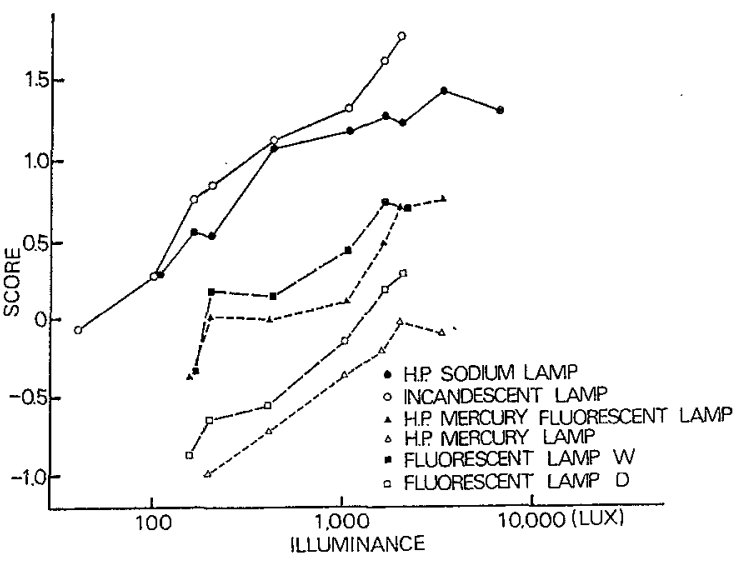

Fig. 11 Scale value of the adjective "warm" as a function of illuminance.

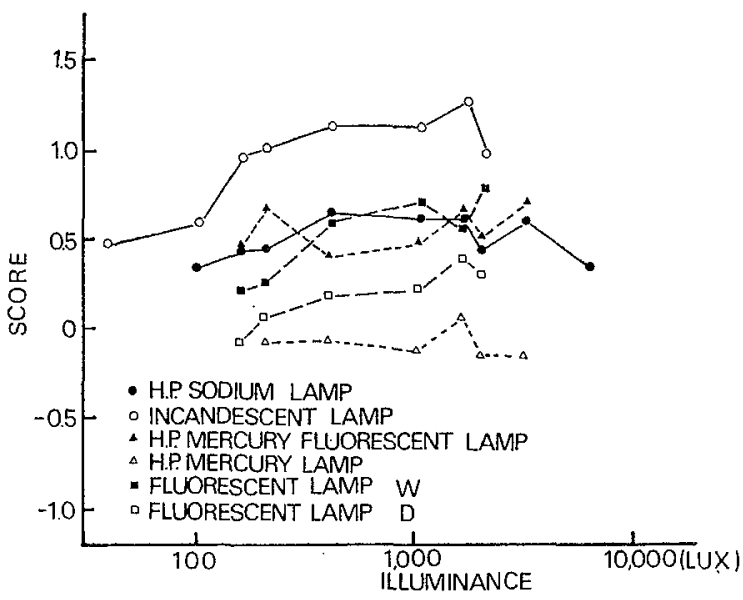

Fig. 12 Scale value of the adjective "soft" as a function of illuminance.

regarding "color favour" (item 24). Thus it may be concluded that illuminance, color rendering index and color temperature are important factors about pleasantness.

The subjective values for "warm" and "soft" scales are plotted against illuminance in Figs. 11 and 12. The value of "warm" scale increases with the increase of illuminance, and the value varies with the increase of color temperature. Under the conditions of low color temperature lamps, the value is higher than that of high color temperature lamps. The feeling of "warm" is affected by the wave length of the light according to the investigations of warm color. Therefore, our finding agrees quite well with those investigations. On the other hand, the subjective value of "soft" scale may depend upon color temperature and color rendering index. The value decreases with the increase of color temperature except the high pressure sodium lamp and the high pressure mercury lamp.

In Fig. 13, the scale value of "the brightness for the office" (item 9) is plotted. The value increases with the increase of illuminance, but there is a maximum point at about $2,000 \mathrm{~lx}$ under all conditions. 


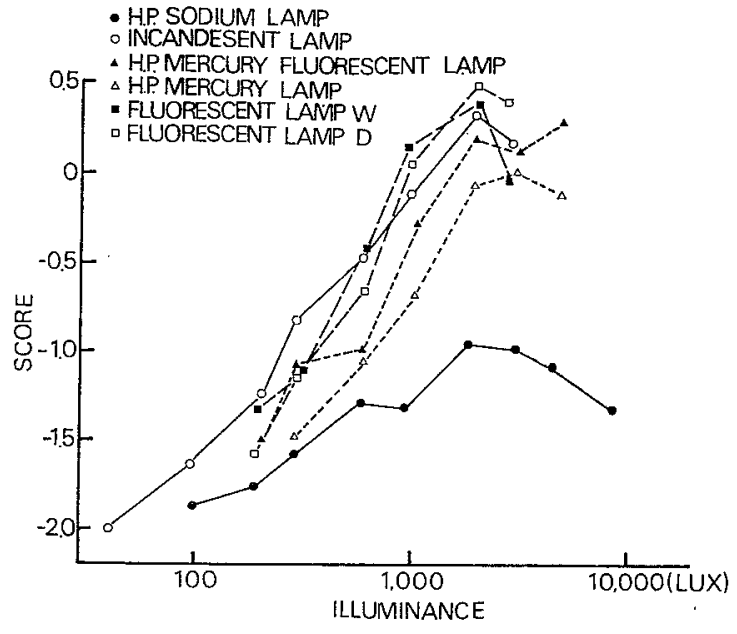

Fig. 13 Scale value of "the brightness for the office" (item 9) as a function of illuminance.

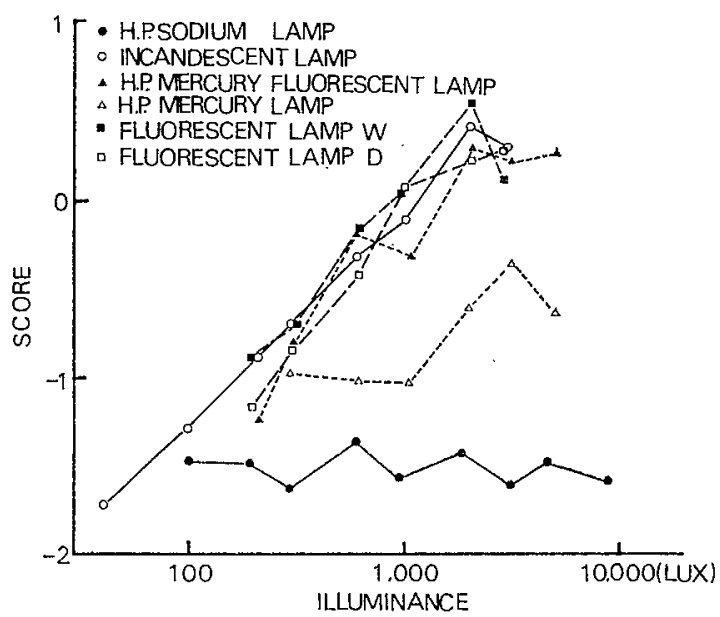

Fig. 14 Scale value of "the total atmosphere of the room" (item 25) as a function of illuminance.

It may be considered that the decrease of the value beyond $2,000 \mathrm{~lx}$ depends upon discomfort glare. This data is quite similar to that in Fig. 9, which is obtained from the scale of "pleasant" in the "image" test. Similar results are also obtained from items 23 and 25 in the "evaluation" test. Fig. 14 shows the result of item 25, "the total atmosphere of the room". Evidently, the effect of color rendering is observed. That is, the high pressure sodium lamp and the high pressure mercury lamp which have low color rendering index are not desired by the subjects. From these findings, it can be concluded that illuminance of about $2,000 \mathrm{Ix}$ will be most desirable in the case of the office if discomfort glare is avoided. Illuminance of about $2,000 \mathrm{~lx}$ will be an upper limit when an approach to daylight is desired by the use of high color temperature lamps for interior illumination.

Fig. 15 shows the relationship between the scale value of "discomfort glare" (item 11) and illuminance. The scale value does not vary in spite of the change of illuminance. However, the value begins to decrease when the illuminance increases beyond $1,000 \mathrm{~lx}$. This tendency is clearly observed under

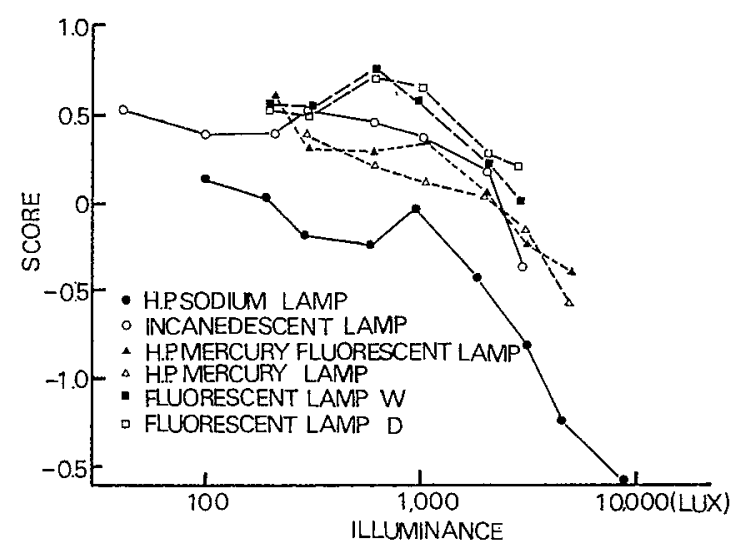

Fig. 15 Scale value of "the discomfort glare" (item 11) as a function of illuminance.

the conditions of high pressure lamps. On the other hand, in the case of the fluorescent lamps, the degree of glare is smaller than the others. So far as our study is concerned, the high pressure sodium lamp is not desired at many aspects as mentioned above. In this experiment, the subjects observed the inside of the room through the small viewing window. Therefore the degree of glare as can be seen in Fig. 15 might not be applied practically, because the degree of discomfort glare would differ from that in the room.

\section{Summary}

Using a miniature room, the effects of illuminance upon comfortable visual environments of the office were examined under various lighting conditions. Two kinds of questionaire tests, "image" and "evaluation", were used to rate the various aspects of the office. The major results are summarized below.

(1) As the results of principal components analysis, four components were extracted in both tests, accounting for $95 \%$ and $90 \%$ respectively.

(2) The first component of the "image" test represented a dimension of evaluation, which was dependent upon illuminance and color rendering index. The second was related to mental composure. This was considered to reflect the effects of glare. The third, having a concern in warm feeling, was affected by color temperature and color rendering index. No clear relation was found with illuminance, color temperature and color rendering index for the fourth.

(3) Concerning "evaluation", the components of general evaluation, glare, constructional factor and interiors were extracted. The first component was closely related to illuminance and color rendering index. The second was completely dependent upon illuminance. As to the third and the fourth, no relation was found.

(4) The canonical correlation analysis strongly suggested that there are the close relationships between corresponding components of the tests.

(5) A relationship between color temperature and illuminance upon pleasantness did not necessari- 
ly contradict with the Kruithof's data' though a few discrepancies were found.

(6) Among the items of "image" and "evaluation" tests, "bright", "pleasant", "warm" and "soft" ("image"), and "the natural appearance of color", "the brightness for the office", "the total atmosphere of the room" and "discomfort glare" ("evaluation") were examined individually. These examinations made it clear that illuminance, color temperature and color rendering index were important factors for comfortable visual environments. In particular, it was found that the most desirable illuminance for comfortable visual environments was about $2,000 \mathrm{~lx}$, though it might be needed to exclude discomfort glare.

\section{Reference}

(1) Inui, M.: Appraisal of Visual environment., Journal of The Illuminating Engineering Institute of Japan, 54 (1970) $624 \sim 631$ (in Japanese)

(2) Kruithof, A.A.: Tubular Iuminescence lamps for general illumination., Philips Tech. Rev., 6 (1941) 65 96.

(3) Osgood, C.E., Suci, G. J., and Tannenbaum, P.H.: The measurement of the meaning, The Univ. of Illinois Press. (1957).

(4) Oyama, T., Soma, I., Tomiie, T. and Chijiiwa, H.: A study of affective responses to colors., Acta chromatica, 1, (1965) 164.

(5) Tomiie, T.: A study of affective tones of color (I)., Seishin Studies, (1969) 31 32 (in Japanese).

(6) Wake, T., Kamisasa, H. and Oyama, T.: Visual environment and comfort., Report of comfortable visual environment, Illuminating Engineering Institute of Japan. (1973) (in Japanese).

(1977.2.2, 1977.9.24) 